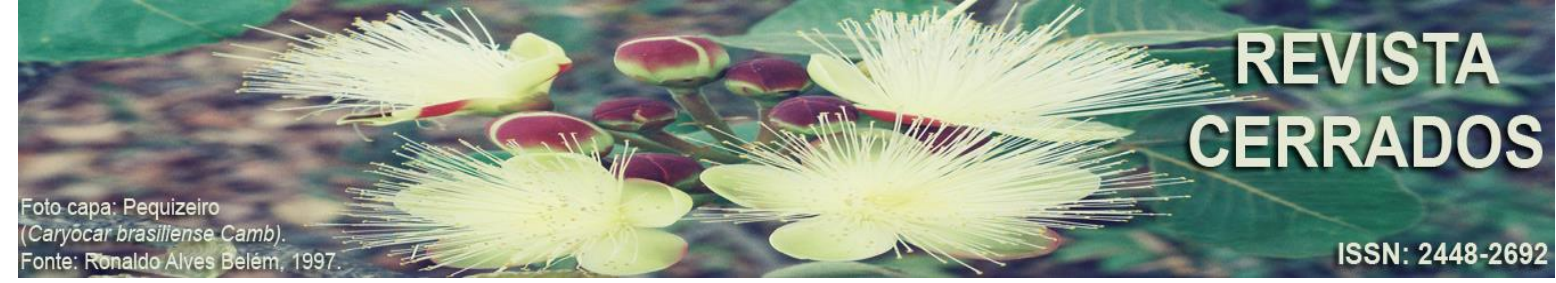

\title{
REDES ORGANIZACIONAIS, SINERGIAS LOCAIS E INTERAÇÕES ESPACIAIS: o projeto Granja Marileusa e a atuação do Grupo Algar em Uberlândia (MG)
}

\section{ORGANIZATIONAL NETWORKING, LOCAL SYNERGIES AND SPATIAL INTERACTIONS: The Granja Marileusa project and the role of the Algar Group in Uberlândia (MG)}

\author{
REDES ORGANIZACIONALES, SINERGIAS LOCALES Y \\ INTERACCIONES ESPACIALES: El proyecto Granja Marileusa y la \\ Actuación del grupo Algar en Uberlândia (MG)
}

\author{
Fernando Fernandes de Oliveira \\ Instituto Federal de Ciência e Tecnologia Goiano - IF/Goiano, Ipameri, Goiás, Brasil \\ E-mail: <fernando.oliveira@ifgoiano.edu.br >. \\ Denis Castilho \\ Universidade Federal de Goiás - UFG, Goiânia, Goiás, Brasil \\ E-mail: <deniscastilho@ hotmail.com>.
}

\begin{abstract}
RESUMO
No âmbito da reestruturação técnico-científica, a organização em rede é baseada na premissa das sinergias locais, da flexibilidade, da cooperação e das interações espaciais. Este texto discute as estratégias de ação do Grupo Algar, uma corporação sediada em Uberlândia (MG), no arranjo de redes organizacionais correlatas às suas principais atividades. Em vista disso, analisa o comando de programas de inovação aberta e os esforços para fomentar, na mencionada cidade, qualificações e sinergias profícuas ao próprio funcionamento. Sobre esse último ponto, a estratégia segue vinculada à prática de incorporação imobiliária que, a partir da refuncionalização de uma gleba periurbana pertencente ao próprio grupo, deu origem ao projeto imobiliário denominado Granja Marileusa. Esse projeto revela uma importante estratégia que potencializa as interações, alimenta efeitos de proximidade, de conexão e de inovação. Frente ao arrefecimento da produção industrial e/ou da venda de bens ligados ao mercado primário, evidencia especialmente uma prática que mira a valorização do capital fundiário angariado nos auspícios do mercado imobiliário.
\end{abstract}

Palavras-chave: Redes organizacionais. Granja Marileusa. Capital imobiliário. Grupo Algar.

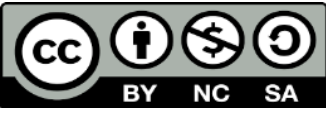


OLIVEIRA, F. F; CASTILHO, D.

Redes organizacionais, sinergias locais e interações espaciais: O projeto Granja Marileusa e a atuação do Grupo Algar em Uberlândia (MG)

\begin{abstract}
Regarding the technical-scientific restructuring, the networking is based on the premises of local synergy, flexibility, cooperation and spatial interactions. This text discusses the action strategies of the Algar Group, a company located in Uberlândia (Minas Gerais State, Brazil), in the arrangement of organization networking correlated to their main activities. Therefore, it analyses the command of open innovation programs and the efforts to promote, in the city mentioned, useful qualifications and synergies to its own functioning. About this last point, the strategy is tied to real estate development practices which, from the refunctionalization of a periurban land belonging to the group itself, gave origin to the real estate project named Granja Marileusa. This project revels an important strategy which potentializes the interactions, it feeds the proximity effects, the connection and innovation ones. Due to the cooling of the industrial production and/or the assets selling linked to the primary market, it shows specially a practice which aims the appreciation of the land capital raised in the auspices of the real estate market.
\end{abstract}

Keywords: Organizational networking. Granja Marileusa. Real estate capital. Algar Group.

\title{
RESUMEN
}

En el ámbito de la reestructuración técnico-científica, la organización en red se basa en la premisa de sinergias locales, de la flexibilidad, de la cooperación y de las interacciones espaciales. Este texto analiza las estrategias de acción del Grupo Algar, una corporación con sede en Uberlândia (estado de Minas Gerais, Brasil), en la conformación de redes organizacionales relacionadas con sus actividades principales. En vista de esto, analiza el comando de los programas de innovación abierta y los esfuerzos para fomentar, en la ciudad mencionada, calificaciones y sinergias útiles para el propio funcionamiento. Con respecto a este último punto, la estrategia sigue vinculada a la práctica de incorporación inmobiliaria, que, desde la refuncionalización de una parcela periurbana perteneciente al propio grupo, dio lugar al proyecto inmobiliario denominado Granja Marileusa. Este proyecto revela una estrategia importante que refuerza las interacciones, fomenta los efectos de proximidad, de conexión y de innovación. Frente a la atenuación de la producción industrial y/o de la venta de bienes vinculados al mercado primario, indica especialmente una práctica que apunta a la valorización del capital de la tierra a través de los auspicios del mercado inmobiliario.

Palabras clave: Redes organizacionales. Granja Marileusa. Capital inmobiliario. Grupo Algar.

\section{INTRODUÇÃO}

Como elementos fundamentais para a articulação dos diversos processos ligados ao desempenho das atividades econômicas, as redes técnicas constituem-se como suportes indispensáveis para as estratégias espaciais executadas por grandes corporações. Disso, 
OLIVEIRA, F. F; CASTILHO, D.

Redes organizacionais, sinergias locais e interações espaciais: O projeto Granja Marileusa e a atuação do Grupo Algar em Uberlândia (MG)

resulta o caráter sociotécnico das estruturas reticulares, compreendidas como os componentes materiais que dão suporte às ações encaminhadas pelos atores da sociedade. Ao integrarem facetas da produção, dos mercados, das finanças e dos fluxos informacionais, as redes técnicas também emergem como instrumentos inseparáveis da organização espacial de uma corporação multilocalizada, seja no contexto intra-empresa, no externo imediato ou no ordenamento que se faz sentir à distância.

Logo, a arquitetura multidivisional das grandes corporações não pode prescindir uso privilegiado das estruturas reticulares. Embasadas por esse suporte técnico, elas meandram pelas especificidades dos subespaços, estabelecem complementaridades com múltiplos atores e induzem especializações que consolidam os seus centros de gestão territorial. A capacidade da empresa para a efetivação de novas estratégias depende, conforme escreve Mazzali (2000, p. 155), “das articulações com os demais agentes que a circundam”, de maneira que os arranjos organizacionais em rede buscam promover a circulação de competências, de conhecimentos e da aprendizagem em contextos espacialmente concentrados.

O escopo do presente texto é o de analisar as estratégias do Grupo Algar para o estabelecimento de redes organizacionais em Uberlândia, cidade que abriga o centro de comando dessa corporação. Para tanto, os procedimentos metodológicos fundamentaram-se em pesquisa bibliográfica e documental, além de trabalhos de campo, de mapeamentos e do tratamento de dados secundários. Estes, foram obtidos de órgãos oficiais, a exemplo de publicações da Prefeitura Municipal de Uberlândia, da Agência Nacional de Energia Elétrica (ANEEL) e da Universidade Federal de Uberlândia (UFU). Ressaltamos, ainda, os sites do Grupo Algar, de empresas parceiras e informações disponibilizadas pelas agências setoriais, tais como a Associação Brasileira de Startups (ABSTARTUP), a Associação Nacional de Entidades Promotoras de Empreendimentos Inovadores (APROTEC), dentre outras.

A primeira sessão discute aspectos da estrutura de governança de corporações multifuncionais/multilocalizadas, da organização em rede e do intento desses atores em condensar vantagens produtivas, tecnológicas e inovativas nos lugares. Na segunda parte, consideramos os conteúdos funcionais e normativos que perseguem adequar a cidade de Uberlândia como um "centro de inovação" e lugar de sinergias em rede. Por sua vez, a terceira parte destaca a recente investida do Grupo Algar nas redes do mercado de venture 
OLIVEIRA, F. F; CASTILHO, D.

Redes organizacionais, sinergias locais e interações espaciais: O projeto Granja Marileusa e a atuação do Grupo Algar em Uberlândia (MG)

capital. Por fim, busca-se evidenciar a edificação do projeto de incorporação imobiliária denominado Granja Marileusa como prática de valorização do capital imobiliário por meio da indução de usos específicos do solo urbano.

\section{CORPORAÇÃO, REDES ORGANIZACIONAIS E OS EFEITOS CIRCULARES DA PROXIMIDADE}

A manutenção das vantagens táticas adquiridas no decurso do desenvolvimento institucional da moderna corporação multifuncional e multilocalizada requereu crescentes difusão espacial e diversificação, uma forma de lidar com o caráter mutável da competição, da inovação tecnológica e da demanda. A performance em diferentes atividades e frentes geográficas, assinala Chandler (1990), garante acesso perene a economias de escala e escopo, que fazem sustentar as taxas de retorno no longo prazo.

Para Harvey (2013), entretanto, trata-se de estratagema que visa conferir equilíbrio à acumulação ampliada dos capitais, na medida em que a descentralização das operações sob o controle da arquitetura gerencial disciplina os aspectos destrutivos da excessiva centralização dos capitais. Torna-se imperativo, ao "metabolismo" da acumulação, um ajuste espacial que o equalize expansivamente. Como organizações cuja finalidade é maximizar a riqueza dos empreendedores (NORTH, 2018), as corporações redefinem constantemente os seus objetivos e meios, com notória força para impor "arranjos organizacionais que lhe são próprios e indutores de especializações produtivas", como bem explica Pires do Rio (2000, p. 103).

Porquanto, as interações espaciais inerentes às diversas tarefas executadas por grandes corporações não prescindem de um complexo feixe de transações que envolvem expressivo número de lugares, atores e consideráveis custos operacionais. Disso, resulta o estabelecimento daquilo que Williamson (1981) chamou de "estrutura de governança", o ordenamento pelo qual toda a rede de unidades operacionais recebe coordenações que minimizem os custos do ato de transacionar. Sob o comando dessa governança, a reprodução dos capitais, na ótica da corporação multilocalizada, demanda a concentração de conhecimento e de aprendizagem em determinadas áreas, com vistas a configurar 
OLIVEIRA, F. F; CASTILHO, D.

Redes organizacionais, sinergias locais e interações espaciais: O projeto Granja Marileusa e a atuação do Grupo Algar em Uberlândia (MG)

interdependências profícuas entre diversos atores econômicos que se beneficiam de competências localmente externalizadas.

Refere-se, nessa condição, aos arranjos organizacionais "em rede", que geram interdependências entre atores com diferentes prerrogativas em poderio econômico e conteúdo funcional. A coordenação de competências específicas visa auferir vantagens diferenciadas no que tange aos processos produtivos, tecnológicos e de inovação num contexto espacialmente concentrado. Ao refletir sobre as redes relacionais e as estruturas de governança, Benko (2009) escreve:

Chama-se "rede" a dimensão espacial de uma forma de regulação das relações entre unidades produtivas, e "governança" o modo de regulação dessas relações que é, em geral, a combinação de diferentes formas: hierarquia, terceirização, parceria, "atmosfera", agências públicas ou parapúblicas (2009, p. 121).

No dinamismo dessas associações em rede, emerge a possibilidade concreta de incorporação de competências sob o domínio de outras firmas, não raro mais enxutas, dinâmicas e flexíveis. Admite-se, dessa forma, a existência de arranjos circulares que potencializam a aglomeração, assim fortalecidos por "um conjunto de processos cumulativos, necessariamente envolvendo algum tipo de retorno crescente, por meio do qual a concentração geográfica pode se auto reforçar" (FUJITA et al 2002, p. 16-17) ${ }^{1}$.

Para a grande corporação, fica garantido acesso perene a respostas rápidas e adaptativas advindas dos diversos atores que consubstanciam uma rede endógena de unidades pequenas e especializadas, o que lhe confere notório poder sobre a gestão do mercado e da tecnologia. Daí, o incentivo desses atores mediante a criação de mecanismos localizados que representem atividades suporte para as suas demandas, seja por meio de ações próprias, como estímulos para a criação de startups, scaleups ${ }^{2}$, de meios para a aprendizagem, inovação e capacitação profissional, ou pelas diversas demandas solicitadas junto ao poder público.

\footnotetext{
${ }^{1} \mathrm{Na}$ opinião desse autor, o reconhecimento de tais sinergias localizadas representa um "renascimento" da geografia econômica, há tempos negligenciada pelos economistas.

${ }^{2}$ Grosso modo, o termo startup compreende a empresas jovens e pequenas, geralmente caracterizadas pelo agrupamento de profissionais em busca de negócios e associações empresariais que operam em setores de atividades dinâmicos e incertos. As scaleups, como versão madura e mais estável de uma startup, caracterizamse pelo crescimento rápido, direcionado e escalar. Segundo critérios utilizados pelo Cadastro Central das Empresas - CEMPRE/IBGE, as scaleups são aquelas que crescem na ordem de $20 \%$ ao ano por um período não inferior a três anos, representando, segundo as Estatísticas de Empreendedorismo publicadas pelo o mencionado órgão, 46\% dos empregos gerados no Brasil no período 2014-2015.
} 
OLIVEIRA, F. F; CASTILHO, D.

Redes organizacionais, sinergias locais e interações espaciais: O projeto Granja Marileusa e a atuação do Grupo Algar em Uberlândia (MG)

O alerta de Mazzali (2000), entretanto, aponta para o caráter dúbio dessas redes de complementaridades, que podem tanto ocasionar progressiva perda de autonomia por parte dos atores menores, que veem a sua identidade dissolvida na amplitude das demandas da grande empresa, quanto na concretização de um ambiente propício a novas oportunidades de aprendizagem, de inovação e de lucratividade. Por essa via de análise, as redes organizacionais localizadas representam componente importante para a elucidação do comportamento dos atores no âmbito das economias regionais. Para a grande corporação, as conexões estabelecidas permitem a formação de "cadeias produtivas que envolvem domínio tecnológico e ampla escala comercial sob a racionalidade da empresa", como anota Pires do Rio (2012, p. 176).

O proeminente papel exercido pelo padrão multidivisional do Grupo Algar na cidade de Uberlândia (MG), o centro da gestão de seu amplo território, pode ser mensurado pela indução de redes relacionais que assegurem acesso constante ao conhecimento sob domínio de outras organizações. Esta corporação, cujas origens remontam ao início da década de 1930, é composta por uma arquitetura multifuncional/multilocalizada extremamente diversificada. Atua, dentre outras funções, nos setores de telecomunicações, agronegócio, turismo e hotelaria, táxi aéreo, segurança patrimonial.

Em 2018, registrou Receita Operacional Líquida da ordem de R\$ 3 bilhões, empregando aproximadamente 20 mil funcionários (ALGAR, 2019). No que concerne ao espaço de atuação, está presente em todas as regiões brasileiras, mantendo posições em países como Argentina, Chile, Colômbia e México. Em que medida, sob ótica das suas capacidades socioeconômicas, técnicas e institucionais, a cidade sede estaria "apta" ao amparo das demandas mais sofisticadas da citada corporação?

\section{REDES ORGANIZACIONAIS EM UBERLÂNDIA: EQUIPAMENTOS E NORMAS}

A compreensão da complexa estrutura multidivisional do Grupo Algar não pode estar desvinculada do contexto espacial. Suas ações meandram pelas especificidades dos subespaços para melhor explorar as potencialidades locais e assim estabelecer relações sinérgicas com diversos atores, induzindo especializações e consolidando centros de gestão territorial. Em Uberlândia, o padrão multifacetado dessa corporação exige a disponibilidade 
OLIVEIRA, F. F; CASTILHO, D.

Redes organizacionais, sinergias locais e interações espaciais: O projeto Granja Marileusa e a atuação do Grupo Algar em Uberlândia (MG)

de redes relacionais que assegurem acesso constante às soluções desenvolvidas por organizações mais enxutas e flexíveis.

Além da atração oportunizada pelas externalidades inerentes, a estratégia busca fomentar, no lugar, um "ecossistema de startups" aderentes às áreas de atuação do conglomerado. Assim, o número de startups sediadas nesse centro urbano torna-se um dado interessante. As características versam sobre firmas em fase inicial de maturação, que desenvolvem serviços ou produtos inovadores, e que possuem potencial de rápido crescimento, embora os riscos de insucesso sejam igualmente altos. Em 2019, Uberlândia possuía 131 startups cadastradas na plataforma da Associação Brasileira de Startups (ABStartups), o que coloca essa cidade como a segunda maior concentração desses empreendimentos no estado de Minas Gerais ${ }^{3}$.

A indução de especializações sofisticadas, cumpre registrar, é fruto das ações coordenadas por atores públicos e privados. Concordando com Fischer (2008, p. 29), são "as empresas, as coletividades territoriais e locais e o Estado" os principais articuladores das estratégias que alteram o conteúdo funcional dos lugares. Logo, a gestação de um ambiente favorável ao desenvolvimento de redes de empresas busca ofertar um conjunto de funções aderentes à natureza das atividades comandadas pelos atores mais proeminentes da cena local.

As informações contidas na publicação intitulada Dados Geoeconômicos de Uberlândia, da Secretaria Municipal de Desenvolvimento Econômico, Inovação e Turismo, indicam que Uberlândia possuía, em 2017, 11 estabelecimentos presenciais de educação superior, dentre instituições públicas e privadas. Juntos, os campi universitários instalados na cidade ofereciam 214 cursos com 46.454 vagas, de forma que o número de alunos matriculados totalizou 69.127, no ano mencionado (UBERLÂNDIA, 2018).

Ganham notoriedade a Universidade Federal de Uberlândia (UFU), o Instituto Federal de Ciência e Tecnologia do Triângulo Mineiro (IFTM), a Universidade de Uberaba (Uniube), a Faculdade Pitágoras, a Universidade do Triângulo (UNITRI), a Escola Superior de Administração, Marketing e Comunicação (ESAMC), a PUC Minas e a Faculdade Una. Essas instituições ofertam um leque variado de cursos de graduação, de pós-graduação (latu

\footnotetext{
${ }^{3}$ A título de comparação, a cidade de São Paulo possui, atualmente, 2.649 startups; o Rio de Janeiro abriga 706, enquanto Belo Horizonte conta com 604 empreendimentos dessa natureza. Quando consideramos cidades de porte similar, Uberlândia destaca-se: centros como São José dos Campos, Ribeirão Preto e Maringá concentram, respectivamente, 97, 59 e 50 startups cadastradas na mencionada plataforma (ABSTARTUPS, 2019).
} 
OLIVEIRA, F. F; CASTILHO, D.

Redes organizacionais, sinergias locais e interações espaciais: O projeto Granja Marileusa e a atuação do Grupo Algar em Uberlândia (MG)

sensu e stricto sensu), e de programas que enfatizam a capacitação técnica. No que se refere às escolas do ensino técnico, além do IFTM, merecem destaque o Serviço Social da Indústria (SESI) e o Serviço Nacional de Aprendizagem Industrial (SENAI), pertencentes ao Sistema FIEMG.

Por estimularem a cooperação entre os atores locais, os programas de mentoria e de incubação ${ }^{4}$ oferecidos por essas instituições são dignos de nota. Em seu aparato organizacional, a Universidade Federal de Uberlândia disponibiliza três incubadoras. A Agência Intelecto $^{5}$ e o Centro de Incubação de Atividades Empreendedoras (CIAEM) desenvolvem ações coordenadas que visam proteger a inovação, promover a transferência de tecnologia e incentivar o desenvolvimento de novos negócios, com ênfase aos que possuem base tecnológica. Por sua vez, o CIEPS-UFU mira subsidiar projetos voltados à economia solidária, apoiados no tripé ensino, pesquisa e extensão. Além dessas, o Núcleo de Empresas Junior da UFU (NEJ) oferece suporte aos diversos planos de empresas juniores desenvolvidos nas unidades acadêmicas da Universidade.

Ainda no domínio dos equipamentos de ensino, ressaltamos os programas de mentoria Unitecne, da Uniube; Ânina Nest, da Una; Agita, Go Minas e Like a Boss, do SEBRAE, todos voltados ao estímulo do empreendedorismo e das parcerias entre atores locais. Há, também, a iniciativa denominada UberHub Code Club, baseada numa rede global de atividades de capacitação semipresencial em computação e desenvolvimento de software. A unidade uberlandense utiliza plataformas concebidas pelas universidades de Harvard, Unicamp e UFU, e conta com o apoio de proeminentes corporações sediadas na cidade ${ }^{6}$.

As entidades representantes do empresariado local também endossam os esforços, tal como sugerem os projetos Aciub Jovem e Empreender, disponibilizados pela Associação Comercial e Industrial de Uberlândia - Aciub. Merecem realce, ademais, duas organizações

\footnotetext{
${ }^{4}$ Segundo a Associação Nacional de Entidades Promotoras de Empreendimentos Inovadores - APROTEC, as incubadoras são estruturas organizacionais direcionadas ao acompanhamento de empreendimentos em estágio inicial de maturação, conferindo apoio às novas iniciativas no acesso de recursos, de conhecimentos e de mercados (APROTEC, 2016).

${ }^{5}$ Atuando desde 2005, essa agência já recebeu 218 depósitos de pedidos de patentes, oriundos das diversas unidades acadêmicas da UFU. O Instituto de Biotecnologia e a Faculdade de Engenharia Mecânica lideram com 57 e 54 pedidos, respectivamente (AGÊNCIA INTELECTO, 2019).

${ }^{6}$ Participam dessa iniciativa de capacitação, dentre outras instituições, as faculdades Una, Pitágoras e Uniube; o Tribanco, do Grupo Martins; diversas startups especializadas em TIC; além de Algar Telecom/Tech.
} 
OLIVEIRA, F. F; CASTILHO, D.

Redes organizacionais, sinergias locais e interações espaciais: O projeto Granja Marileusa e a atuação do Grupo Algar em Uberlândia (MG)

que promovem a conexão entre startups e empresas demandantes. A i9 Uberlândia subsidia startups atuantes em TIC, por meio de consultoria especializada. Por seu turno, a Comunidade Colmeia, estrategicamente, situada no bairro planejado do Grupo Algar, disponibiliza programas de mentoria e pré-aceleração que buscam alinhar as iniciativas assistidas aos requerentes por soluções.

No que tange ao arcabouço institucional ${ }^{7}$, cumpre registar os incentivos dirigidos pela Lei Complementar $n^{\circ}$ 629, de 7 de dezembro de 2017, que sancionou o Programa Inova Uberlândia e criou o Polo Tecnológico Sul. Busca-se, com ela,

fortalecer a competitividade na oferta de serviços de tecnologia e outros correlatos, fomentar o desenvolvimento de empresas de base tecnológica e incentivar a geração e ampliação de postos de trabalho, mediante a concessão de incentivos fiscais em polos e micro polos de tecnologia e serviços (UBERLÂNDIA, 2017).

Assim, as firmas tecnológicas ficam isentas do pagamento do Imposto sobre Propriedade Predial e Territorial Urbana (IPTU), e do Imposto sobre Transmissão de Bens Imóveis - ITBI, referentes à aquisição de imóvel onde a iniciativa será implantada. Outra medida encaminhada pelo executivo municipal reduz a alíquota do Imposto Sobre Serviços (ISS) a 2\%, para empresas com o perfil destacado. O Polo Tecnológico Sul conta com área de $152.845 \mathrm{~m}^{2} ; 57.998 \mathrm{~m}^{2}$ pertencem a áreas de preservação permanente e $39.406 \mathrm{~m}^{2}$ aos 32 lotes já regulamentados, que variam de $600 \mathrm{~m}^{2}$ a $4.850 \mathrm{~m}^{2}$. A Prefeitura Municipal, como de praxe nesses empreendimentos, é a responsável pela adequação infraestrutural da área.

Ao fazer convergir benesses de ordem tributária, imobiliária e de infraestrutura, a municipalidade diminui o peso dos investimentos iniciais a cargo das empresas, tomando para si parte dos gastos de implantação das novas iniciativas. As localidades são, assim, reestruturadas pelo impulso dos governos e das elites empresariais, ansiosas por tencionar o que Castells (2005, p. 470) denomina como "redes de cooperação entre as instituições regionais e entre as empresas localizadas na área". Chama a atenção, como alerta Harvey (2005, p. 230), o encaminhamento de estratégias orientadas para criarem padrões locais de investimento,

\footnotetext{
${ }^{7} \mathrm{Na}$ esfera da União, convém assinalar a Lei no 10.973 de 2004, que dispõe dos incentivos à inovação e à pesquisa científica e tecnológica. Dentre outras atribuições, a normativa fomenta a criação de incubadoras e de parques tecnológicos.
} 
OLIVEIRA, F. F; CASTILHO, D.

Redes organizacionais, sinergias locais e interações espaciais: O projeto Granja Marileusa e a atuação do Grupo Algar em Uberlândia (MG)

não apenas em infraestruturas físicas, como transportes e comunicações, mas também em infraestruturas sociais de educação, ciência e tecnologia, controle social, cultura e qualidade de vida. O propósito é gerar sinergia suficiente no processo de urbanização, para que se criem e se obtenham rendas monopolistas tanto pelos interesses privados como pelos poderes estatais.

Os elementos citados oferecem uma ideia da dimensão política das tessituras atadas para multiplicar as vantagens circulares em Uberlândia, cidade sede do Grupo Algar. Analisemos, em perspectiva, as ações mais incisivas dessa corporação para o desenvolvimento de redes de complementaridades nos pontos onde concentra os seus núcleos decisórios.

\section{A ATUAÇÃo DO GRUPO ALGAR EM VENTURE CAPITAL: A GRANDE CORPORAÇÃO SOB A ÉGIDE DA ORGANIZAÇÃO EM REDE}

O ano de 2016 marcou a entrada do Grupo Algar no mercado brasileiro de venture capital $^{8}$, com o ingresso no fundo denominado "BR Startups". Estabelecida no ano de 2013, a iniciativa reúne investidores do calibre de Microsoft, Monsanto, Banco do Brasil e Banco Votorantim, dentre outras grandes corporações. Sua carteira de capitais objetiva acelerar o desenvolvimento de empresas em fase inicial de consolidação, que desenvolvam serviços e/ou produtos inovadores e que gerem sinergias com as organizações que aportam os recursos. Grosso modo, as áreas prioritárias do BR Startups versam sobre telecomunicações, TIC, tecnologias para a agricultura, energias renováveis, mobilidade urbana e segurança pública.

Também em 2016, ocorreu a concepção da Algar Ventures, subsidiária responsável por promover a aceleração de empreendimentos com considerável potencial de inovação e crescimento, tendo por base a própria estrutura multidivisional do conglomerado. Dois anos antes, entretanto, a Alsol Energias Renováveis foi a primeira startup acelerada pelo Grupo Algar. Sediada em Uberlândia, essa empresa é especializada na geração de energia elétrica a partir de fontes alternativas e renováveis, com soluções voltadas para residências, firmas de portes variados e estabelecimentos rurais. Desenvolve, desde 2012, projetos de

\footnotetext{
${ }^{8}$ A geógrafa Maria Terezinha Gomes (2019) expõe uma característica interessante desse mercado no Brasil: a considerável presença dos fundos estatais. Relata a autora que, em 2016, o país possuía 134 gestores que operavam 349 veículos. Destes, 43 eram encabeçados por BNDES, enquanto a Financiadora de Estudos e Projetos (FINEP), participava de outros 33 fundos gestores (GOMES, 2019).
} 
OLIVEIRA, F. F; CASTILHO, D.

Redes organizacionais, sinergias locais e interações espaciais: O projeto Granja Marileusa e a atuação do Grupo Algar em Uberlândia (MG)

captação da energia solar por meio usinas fotovoltaicas; de biogás, a partir de esterco de víveres e, quando possível, pela combinação dessas duas fontes (ALGAR, 2016).

Subsidiada pela grande corporação, a Alsol cresceu de forma rápida, tornando-se a maior geradora de energia fotovoltaica do país. Atualmente, possui escritórios em Goiânia e Brasília, além da sede em Uberlândia. Os ganhos em escala podem ser percebidos na queda dos custos de instalação por Whatt-pico $(\mathrm{Wp})$, que corresponde à medida utilizada para aferir a potência das placas fotovoltaicas: de 2012 a 2018, houve redução de 45,2\% nos custos mencionados, como mostra a Tabela 1. Segundo Aneel (2018), o aumento registrado em 2018 deve-se ao impacto da variação cambial verificada nesse no período, o que encareceu os insumos importados ${ }^{9}$. Ademais, a evolução dos números relativos à potência acumulada é exposta, denotando o expressivo crescimento do empreendimento acelerado pelo Grupo Algar.

TABELA 1 - Alsol: redução dos custos de instalação e expansão da potência acumulada (2012-2018)

\begin{tabular}{c|c|c}
\hline Ano & Custo de instalação por Wp (em R\$) & Potência Acumulada \\
\hline 2012 & 11,50 & $0,41 \mathrm{MWp}$ \\
\hline 2013 & 10,00 & $1,81 \mathrm{MWp}$ \\
\hline 2014 & 8,12 & $4,23 \mathrm{MWp}$ \\
\hline 2015 & 7,44 & $13,77 \mathrm{MWp}$ \\
\hline 2016 & 6,95 & $61,98 \mathrm{MWp}$ \\
\hline 2017 & 5,48 & $182,33 \mathrm{MWp}$ \\
\hline 2018 & 6,30 & $304,78 \mathrm{MWp}$ \\
\hline
\end{tabular}

Fonte: ANEEL (2018). Organizado pelos autores.

Em 2016, a Alsol possuía 2.212.521 unidades consumidoras residenciais, 93.143 em estabelecimentos comerciais e 70.000 em plantas industriais; assim espalhadas pelos estados de Minas Gerais, São Paulo, Rio de Janeiro, Paraná, Goiás, Ceará, Rio Grande do

\footnotetext{
${ }^{9}$ O Banco de Dados Integrados da Prefeitura Municipal de Uberlândia (BDI, 2018) inclui a Alsol como uma das principais firmas importadoras com sede no município.
} 
OLIVEIRA, F. F; CASTILHO, D.

Redes organizacionais, sinergias locais e interações espaciais: O projeto Granja Marileusa e a atuação do Grupo Algar em Uberlândia (MG)

Norte, Piauí e Distrito Federal (ANEEL, 2018). Tal crescimento aguçou o interesse do Grupo Energisa, que comunicou a aquisição de $87 \%$ do capital da Alsol em junho do presente ano. Essa corporação, que possui largo histórico de atuação no mercado brasileiro de geração e distribuição de energia elétrica ${ }^{10}$, tornou-se detentora majoritária da empresa acelerada, pelo montante de R\$ 11,7 milhões (ENERGISA, 2019a). O Grupo Algar manteve participação de 10\% do negócio, enquanto o idealizador da Alsol conservou 3\% de seu capital.

Ainda no que concerne à atuação da Algar Ventures, outras duas empresas aceleradas merecem destaque: Sensix Agro e NetSupport. A primeira, desenvolve competências em agricultura de precisão no lastro da produção agrícola realizada por Algar Farming $^{11}$, no Triângulo Mineiro. Essa startup emprega aeronaves do tipo RPAS (Remotely Piloted Aicraft System), popularmente conhecidas como "drone". Por seu turno, a Netsupport é especializada em prover suporte técnico em tecnologia da informação de modo remoto, para empresas de portes variados. A ênfase, entretanto, recai sobre as pequenas e médias firmas, não raro carentes desse tipo de intervenção.

Outrossim, a estratégia do Grupo Algar no campo das sinergias em rede é enfatizada pelo programa denominado Algar Ventures Open, uma iniciativa de inovação aberta. O projeto foi desenvolvido em parceria com a Endeavor, uma organização multinacional especializada no desenvolvimento de empreendimentos com possibilidades substanciais de crescimento. Do total de 640 startups e scaleups inscritas, 15 foram selecionadas pelo programa, que priorizou aquelas aderentes aos segmentos já explorados pela grande corporação. Durante os seis meses de duração do programa, as firmas aceleradas registraram crescimento médio de $61 \%$ no número de clientes e de $103 \%$ no que pertence ao faturamento (DIÁRIO DO COMÉRCIO, 2018). O Quadro 1 lista as firmas aceleradas, assim como as suas áreas de atuação e as cidades sede.

\footnotetext{
${ }^{10}$ Fundado em Cataguases (MG) no ano de 1905, o Grupo Energisa é, atualmente, o quinto maior distribuidor de energia do país, atendendo aproximadamente 7,7 milhões de consumidores em 11 estados brasileiros. Além dos ativos de produção e distribuição de energia, presta serviços de comercialização de energia, construção, e manutenção de redes elétricas, desenvolvimento de estudos de geração de energia, dentre outras atividades referentes ao setor elétrico (ENERGISA, 2019b).

${ }^{11}$ Subsidiária do braço agroalimentar do Grupo Algar, a Algar Farming atua na produção de commodities agrícolas em fazendas do próprio Grupo, localizadas em municípios do Triângulo Mineiro e Mato Grosso do Sul. Em 2017, a Algar Farming cultivava 13.042 hectares (soja, milho e sorgo), além de um rebanho de 8.500 cabeças de gado de corte (ALGAR, 2019).
} 
OLIVEIRA, F. F; CASTILHO, D.

Redes organizacionais, sinergias locais e interações espaciais: O projeto Granja Marileusa e a atuação do Grupo Algar em Uberlândia (MG)

QUADRO 1 - Firmas selecionadas pelo programa Algar Venture Open, 2018

\begin{tabular}{|c|c|c|}
\hline Startup /scaleup selecionada & Atividade desenvolvida & Sede \\
\hline Altave & $\begin{array}{l}\text { Soluções em monitoramento aéreo de } \\
\text { alvos, georreferenciamento e imageamento }\end{array}$ & São José dos Campos (SP) \\
\hline Beblüe & $\begin{array}{l}\text { Ferramentas de pagamento e fidelização de } \\
\text { clientes }\end{array}$ & São Paulo (SP) \\
\hline BlueSol & $\begin{array}{l}\text { Capacitação técnica (remota e presencial) } \\
\text { de profissionais em energia solar }\end{array}$ & Ribeirão Preto (SP) \\
\hline Cobli & Tecnologia em gestão de frota & São Paulo (SP) \\
\hline Guichê Virtual & $\begin{array}{l}\text { Plataforma online para compra e venda de } \\
\text { passagens de ônibus }\end{array}$ & Uberlândia (MG) \\
\hline Home Agent & $\begin{array}{l}\text { Serviços de call center via home offcie } \\
\text { (trabalho em casa) }\end{array}$ & São Paulo (SP) \\
\hline Lean Survey & $\begin{array}{l}\text { Aplicativo baseado em smartphone para a } \\
\text { realização de pesquisas terceirizadas }\end{array}$ & São Paulo (SP) \\
\hline Liv Up & E-commerce de alimentos congelados & São Paulo (SP) \\
\hline Nama & $\begin{array}{l}\text { Canais de atendimento automatizados e } \\
\text { operados por inteligência artificial }\end{array}$ & São Paulo (SP) \\
\hline Newatt & $\begin{array}{l}\text { Gerenciamento de consumo de energia } \\
\text { elétrica via software }\end{array}$ & Belo Horizonte (MG) \\
\hline Sensedia & $\begin{array}{l}\text { Plataforma para gerenciamento de API } \\
\text { (rotinas de programação) }\end{array}$ & Campinas (SP) \\
\hline Sensix & $\begin{array}{l}\text { Agricultura de precisão via aeronaves não } \\
\text { tripuladas (drones) }\end{array}$ & Uberlândia (MG) \\
\hline SmartMEI & $\begin{array}{l}\text { Aplicativo de gerenciamento financeiro } \\
\text { para microempreendedores }\end{array}$ & São Paulo (SP) \\
\hline Systax Inteligência Fiscal & $\begin{array}{l}\text { Plataforma que reúne soluções em } \\
\text { informação tributária/fiscal }\end{array}$ & São Paulo (SP) \\
\hline Skore & $\begin{array}{l}\text { Plataforma de incorporação de conteúdos } \\
\text { para treinamento/aprendizagem de equipes }\end{array}$ & São Paulo (SP) \\
\hline
\end{tabular}

Fonte: Adaptado de BIT MAGAZINE (2019). Organizado pelos autores.

O Brain Open, por sua vez, representa uma iniciativa de inovação aberta executada pela Algar Telecom, em parceria com as consultorias especializadas ACE e IBI (Israel Brazil Innovations). Sediado no Algar CSC, em Uberlândia, e contando com uma filial em São Paulo (SP), o Brain enfoca o desenvolvimento de competências em subáreas das 
OLIVEIRA, F. F; CASTILHO, D.

Redes organizacionais, sinergias locais e interações espaciais: O projeto Granja Marileusa e a atuação do Grupo Algar em Uberlândia (MG)

tecnologias de informação e comunicação, com ênfase em internet das coisas (IoT), proteção de redes de computadores (cyber security) e computação em nuvem (cloud) (ALGAR TELECOM, 2018).

Uma grande corporação, ao multiplicar as redes de interdependências junto aos seus centros de gestão territorial, atua para reforçar o controle sobre as atividades distintas de dada região. A particularidade das práticas do Grupo Algar para o apoio de complementaridades endógenas ganhou contornos evidentes na morfologia da cidade de Uberlândia, evidenciando o peso das práticas territoriais desta corporação. Contudo, e para além da assertiva que reforça as vantagens circulares da aglomeração, representa evidente estratégia de valorização do capital imobiliário e de obtenção de renda derivada da indução de usos específicos do solo urbano.

\section{SINERGIAS LOCAIS E INCORPORAÇÃO IMOBILIÁRIA: A PRODUÇÃO DO PROJETO GRANJA MARILEUSA}

As consequências geográficas das iniciativas de inovação aberta são evidentes. Rufino (2019) pontua a crescente atuação de grandes grupos econômicos, que não as tradicionais empreiteiras que operam no país, nos processos de produção do espaço urbano. Além dos sofisticados mecanismos financeiros de que dispõem, a autora salienta a patente influência desses atores na definição das políticas públicas de intervenção nos espaços urbanos, exigindo arranjos institucionais que potencializem uma condição longeva dos retornos. Em suas palavras,

\footnotetext{
a ideia de associar grandes empreendimentos imobiliários a processos de desenvolvimento local vai também sendo reforçada nos instrumentos de planejamento, que dão legitimidade e legalidade a essa nova lógica de produção da cidade (RUFINO, 2019, p. 395).
}

Próximo a essa perspectiva, destacamos o conjunto de associações que deram origem ao empreendimento urbanístico "Granja Marileusa", cuja configuração dos principais adendos é retratada pela Figura 1. O projeto de incorporação imobiliária visa criar um "cluster" corporativo localizado no alto do setor leste de Uberlândia, na área da antiga 
OLIVEIRA, F. F; CASTILHO, D.

Redes organizacionais, sinergias locais e interações espaciais: O projeto Granja Marileusa e a atuação do Grupo Algar em Uberlândia (MG)

fazenda Marileusa ${ }^{12}$, de Alexandrino Garcia. Presume-se, como na assertiva de Castells (2005, p. 481), consolidar um "meio de inovação" que assegure "comunicação de ideias, circulação de trabalho e troca de experiências sobre inovação tecnológica e iniciativas empresariais arrojadas". Encontram-se ali, dentre outros equipamentos, a sede do Grupo Algar, instalações da Algar Tech, da Unialgar, do Algar CSC, e uma galeria comercial, como mostra a Figura 2.

Figura 1 - Uberlândia: delimitação do Granja Marileusa e principais equipamentos, 2019

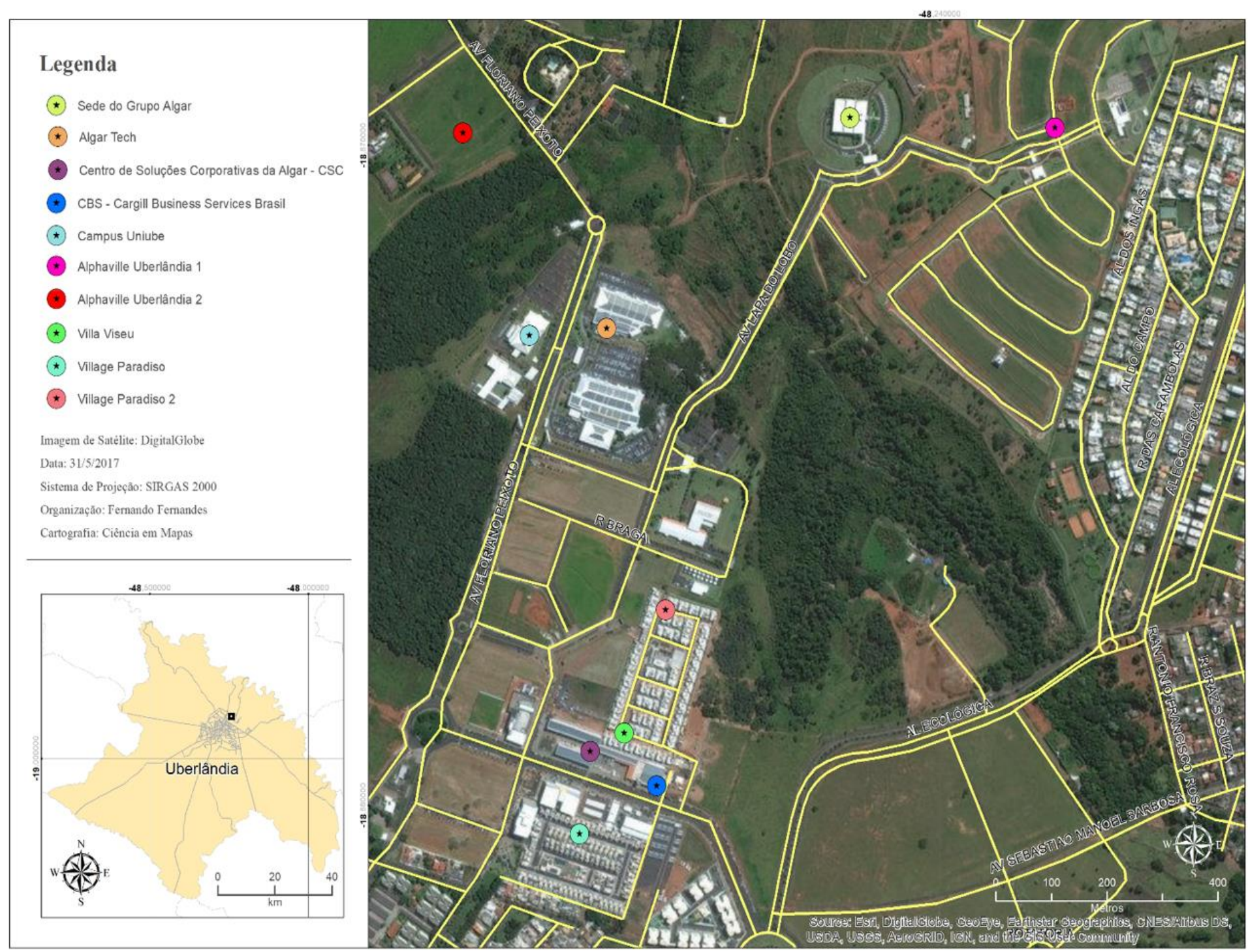

Fonte: Dos autores, 2019.

\footnotetext{
12 "Marileusa” remete à junção dos nomes de Maria e Eleusa, esposa e filha de Alexandrino Garcia. Segundo Silva (1993), a fazenda Marileusa possuía aproximadamente 140 alqueires. Num depoimento ao site Museu da Pessoa (2004), Eleusa Garcia conta que a propriedade foi adquirida em 1950.
} 
OLIVEIRA, F. F; CASTILHO, D.

Redes organizacionais, sinergias locais e interações espaciais: O projeto Granja Marileusa e a atuação do Grupo Algar em Uberlândia (MG)

Figura 2 - sede do Grupo Algar (A); unidades da Algar Tech (B) e Algar CSC (C) e galeria comercial Villa Viseu (D)

A B

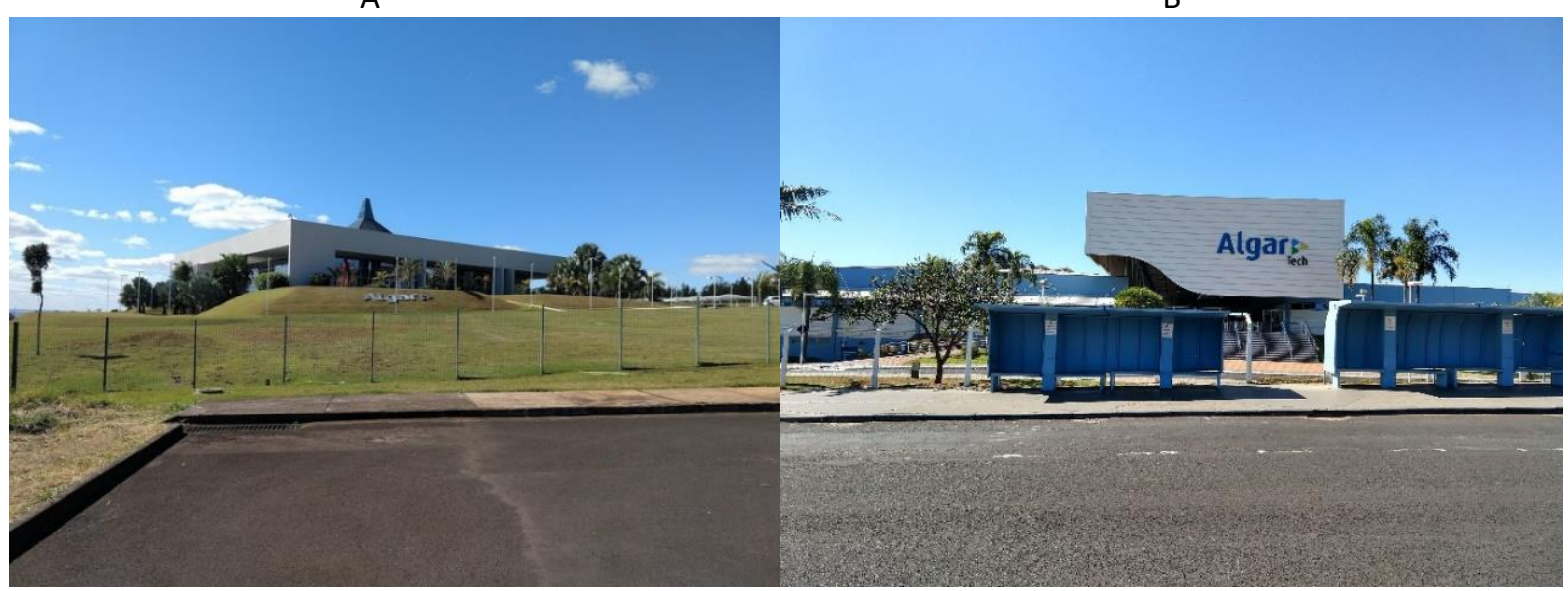

C D

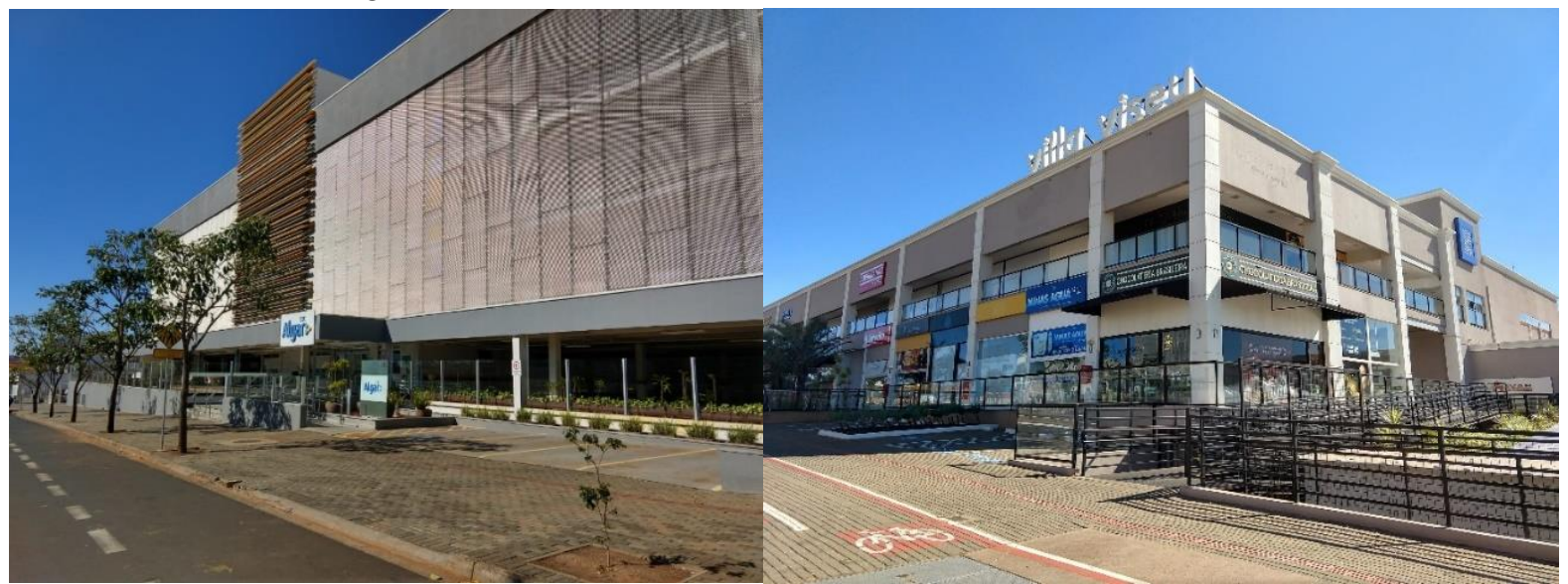

Fonte: dos autores (set. 2019).

O desenvolvimento do bairro planejado requereu a participação de consultorias especializadas em mercado imobiliário. Destacam-se a Urban Systems, que desenvolve diagnósticos de viabilidade de empreendimentos desse tipo, e a empresa de arquitetura De Founier, responsável pela concepção do projeto urbanístico. As notas publicitárias expressam o conceito vislumbrado, que busca estabelecer um "Distrito de Inovação" pautado em usos múltiplos e complementares do espaço ali concebido, de maneira que seja possível "morar, viver, trabalhar, fazer negócios e inovar" (GRANJA MARILEUSA, 2019). Segundo informações disponibilizadas por De Founier (2019), a primeira fase do empreendimento Granja Marileusa conta com estrutura de 224 unidades hoteleiras, 1.086 unidades residenciais e 1.028 unidades comerciais. 
OLIVEIRA, F. F; CASTILHO, D.

Redes organizacionais, sinergias locais e interações espaciais: O projeto Granja Marileusa e a atuação do Grupo Algar em Uberlândia (MG)

Destacam-se, ainda, uma unidade administrativa da Cargill e um campus da Universidade de Uberaba (Uniube), instalado num prédio pertencente ao próprio Grupo Algar. A parceria que possibilitou o Campus Uniube Marileusa ${ }^{13}$ persegue o ideário de reforçar os pressupostos da proximidade e das interações socioespaciais tecidas entre empresas de portes e segmentos variados, estabelecimentos de ensino e serviços diversificados, como sugere a Figura 3. O ambiente, na conjectura apresentada pelo plano, deve ser um "catalisador da diversidade, consistindo em lugares de encontro, com edifícios e equipamentos adequados à escala do pedestre" (DE FOUNIER, 2019); onde a arquitetura privilegie o encontro cotidiano e a convivência (GRANJA MARILEUSA, 2019).

Figura 3 - Uberlândia: proximidade da Algar Tech e do campus Uniube Marileusa (A) e frente do campus Uniube Marileusa (B)

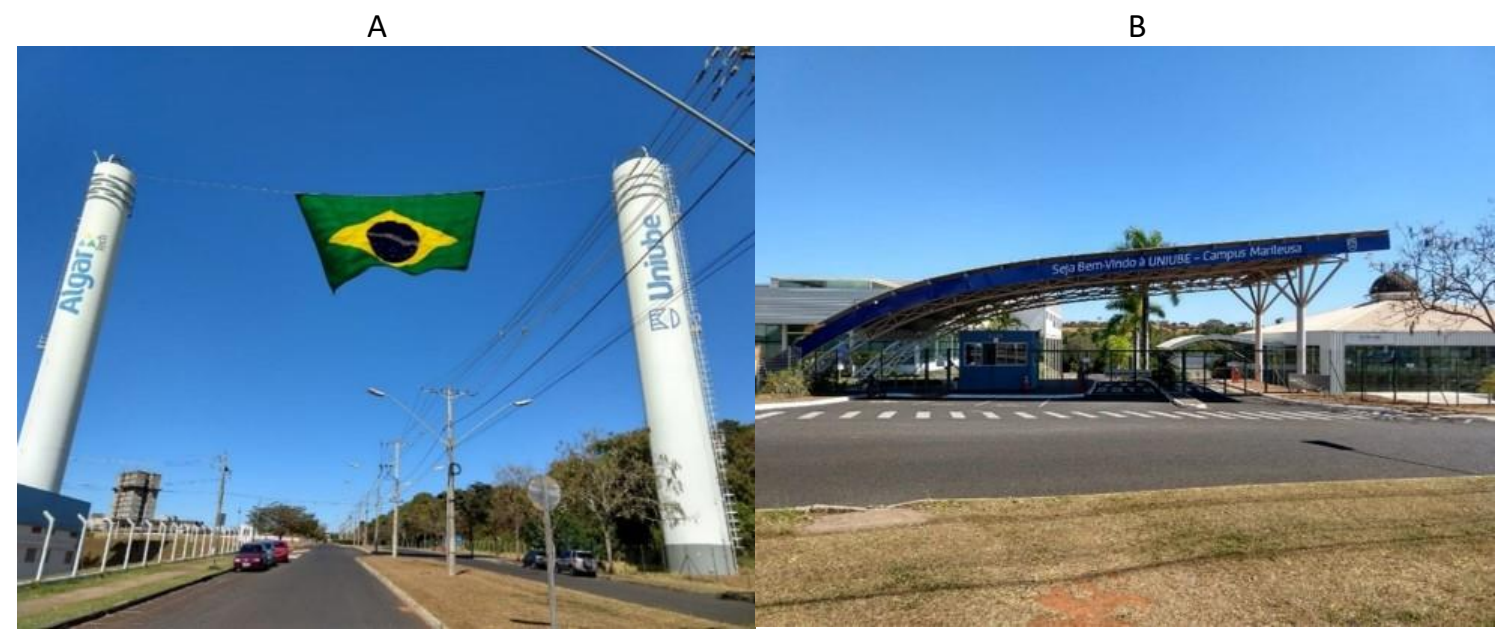

Fonte: dos autores (set. 2019).

Não obstante, a lógica dos empreendimentos imobiliários atraídos para compor as estruturas habitacionais do bairro planejado destoa dos pretenciosos slogans. O modelo de habitação disponibilizado até o momento corresponde, majoritariamente, aos condomínios horizontais de médio e alto padrão arquitetônico, caracterizados por suas áreas de amenidades e equipamentos de lazer, de segurança e de conveniência. Foi possível perceber duas unidades do residencial denominado Village Paradiso, edificados pela Realiza Construtora, pertencente

\footnotetext{
${ }^{13}$ Segundo reportagem veiculada por IstoÉ Dinheiro (2019), a parceria entre Uniube e Algar Tech exigiu que as grades dos cursos de engenharia oferecidos na unidade Marileusa fossem reestruturados para que recebessem formulações em inteligência artificial desenvolvidas pela subsidiária do Grupo Algar. O campus Uniube Marileusa disponibiliza, dentre outros cursos, as engenharias civil, elétrica, de produção e de computação.
} 
OLIVEIRA, F. F; CASTILHO, D.

Redes organizacionais, sinergias locais e interações espaciais: O projeto Granja Marileusa e a atuação do Grupo Algar em Uberlândia (MG)

ao capital local. Juntos, os condomínios entregam 200 sobrados que variam de $142 \mathrm{~m}^{2}$ a $176 \mathrm{~m}^{2}$ (GRANJA MARILEUSA, 2019), amparados por funções diferenciadas e que remetem à exclusividade.

Além desses, o núcleo do Granja Marileusa comporta dois projetos da marca Alphaville Urbanismo, cujos empreendimentos são reconhecidos pela complexidade e distinção funcional. Se somadas, as glebas incorporadas por Alphaville Urbanismo correspondem a $368.979 \mathrm{~m}^{2}$, que disponibilizam 518 unidades imobiliárias de $275 \mathrm{~m}^{2}$ cada, em meio a $50.214 \mathrm{~m}^{2}$ de áreas verdes (GRANJA MARILEUSA, 2019). Difícil imaginar, nessa ótica, que o padrão de moradia apresentado pelos condomínios horizontais, em sua ênfase no exclusivo, nas amenidades e na fortificação, seja alinhado às premissas da interação e da convivência no espaço urbano alardeadas pelo conteúdo publicitário do projeto. Por seu turno, a Figura 4 exibe duas das unidades de condomínios horizontais instalados no Granja Marileusa.

Figura 4 - condomínios horizontais Village Paradiso I (A) e Alphaville II (B)

A B

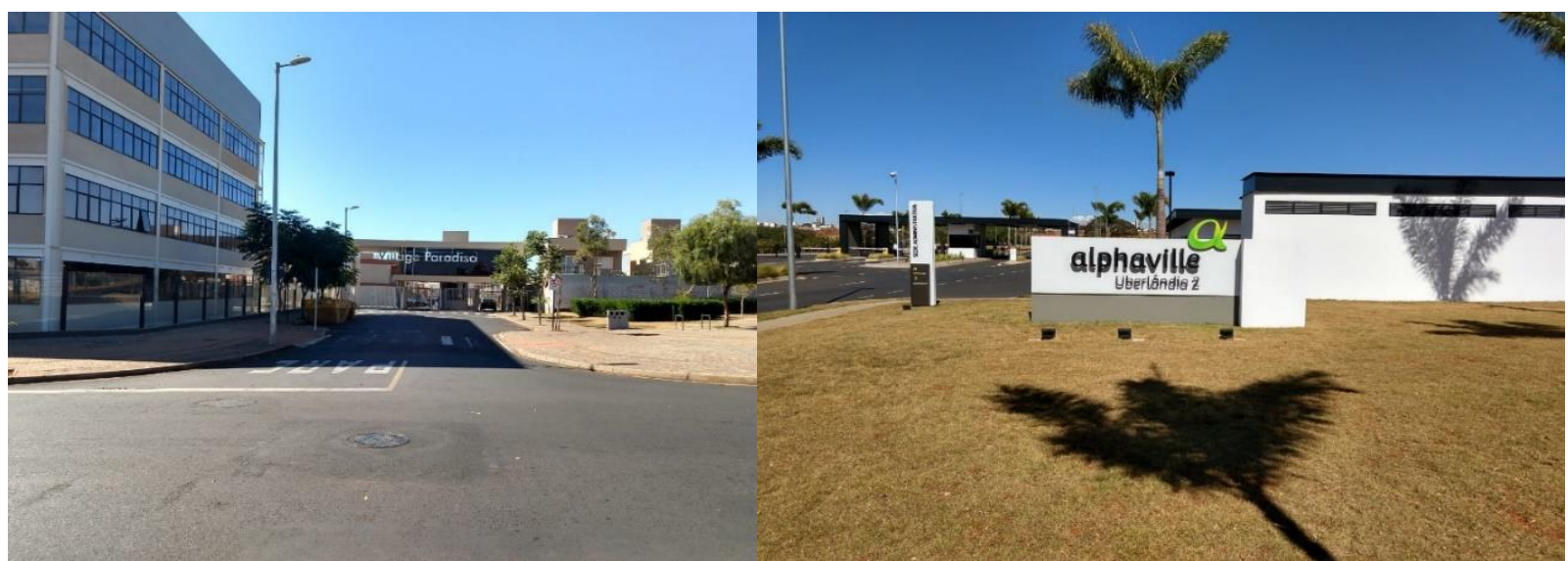

Fonte: dos autores (set. 2019).

Há, entretanto, na paisagem que se processa no Granja Marileusa, empreendimentos imobiliários mais modestos do que os ruidosos Alphaville. Trata-se dos condomínios verticais em fase de construção, tal como o Solar do Cerrado, que será composto por quatro torres. Juntas, somarão 208 apartamentos de dois ou três quartos, cujas metragens variam entre $60 \mathrm{~m}^{2}$ e $73 \mathrm{~m}^{2}$, além dos equipamentos e das comodidades internas diferenciadas. Por sua vez, o condomínio Terraço Gaia deterá duas torres articuladas e apartamentos ainda 
OLIVEIRA, F. F; CASTILHO, D.

Redes organizacionais, sinergias locais e interações espaciais: O projeto Granja Marileusa e a atuação do Grupo Algar em Uberlândia (MG)

menores, com 50m² de área privativa (GRANJA MARILEUSA, 2019). Além das estruturas habitacionais, o bairro planejado conta com um laboratório para exames médicos, uma unidade da rede de supermercados "Bahamas", do Colégio Mackenzie de educação básica, além de outros serviços. A Figura 5 retrata o espaço denominado Casa Garcia, cuja construção contou com aportes do BNDES e do BDMG.

\section{Figura 5 - Uberlândia: Casa Garcia para eventos (A) e (B)}

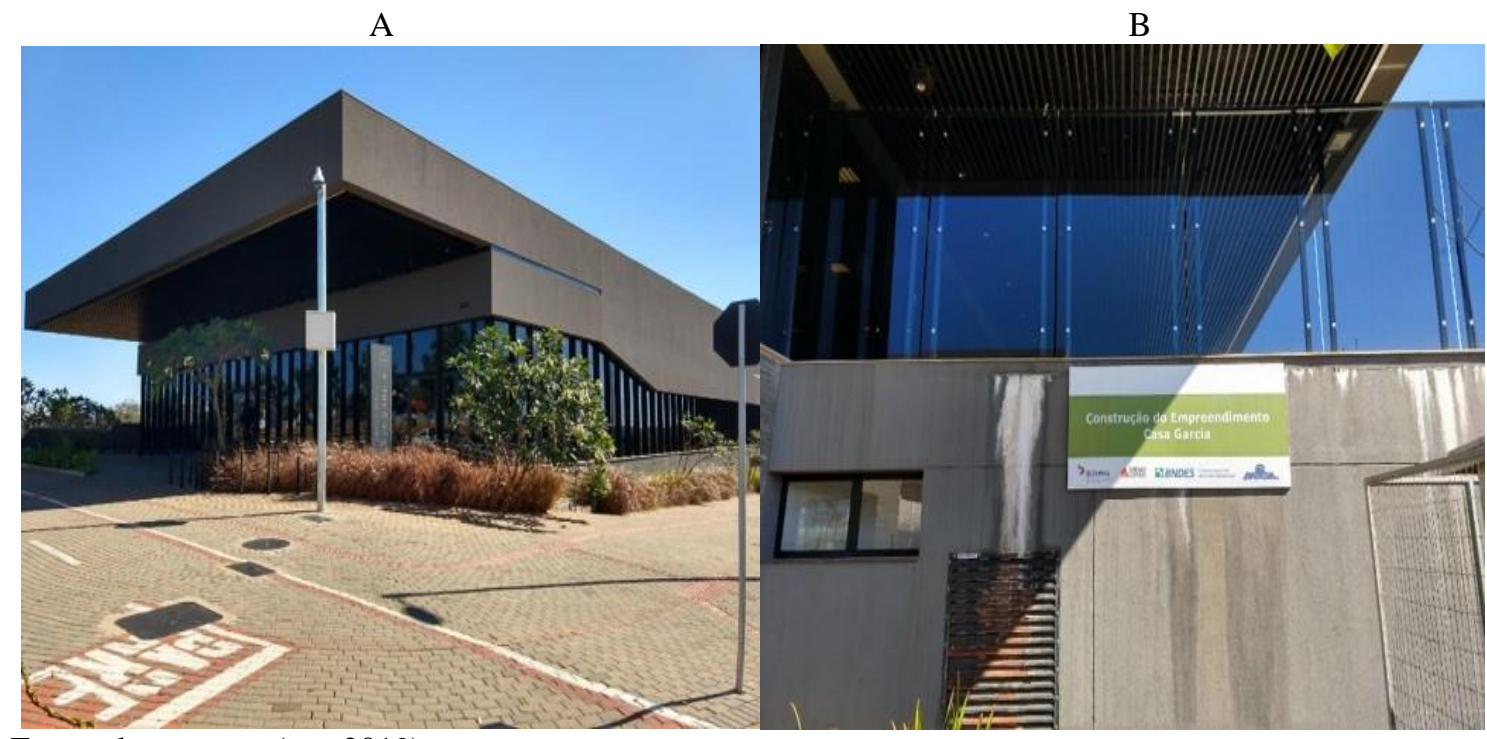

Fonte: dos autores (set. 2019).

Como exposto, a proposta de setorização do bairro planejado almeja estabelecer uma coesão funcional que integre os condomínios horizontais e verticais aos equipamentos comerciais, empresariais, de serviços e de lazer. Não prescinde, como reitera a publicidade, da existência de objetos técnicos que atendam aos imperativos da conectividade, da fluidez e da mobilidade. Segundo Santos (2012, p. 274):

Criam-se objetos e lugares destinados a favorecer a fluidez [...]. Constroem-se edifícios temáticos, bairros inteligentes, tecnopolos. Esses objetos transmitem valor às atividades que deles se utilizam. Nesse caso, podemos dizer que eles "circulam". É como se, também, fossem fluxos.

As informações elencadas nos autorizam inferir que a funcionalidade do empreendimento urbanístico do Grupo Algar atende a dois aspectos elementares. O primeiro refere-se à confecção de redes organizacionais que potencializem as interações entre as firmas, na expectativa de que os efeitos da proximidade gerem um know-how concentrado. Ao 
OLIVEIRA, F. F; CASTILHO, D.

Redes organizacionais, sinergias locais e interações espaciais: O projeto Granja Marileusa e a atuação do Grupo Algar em Uberlândia (MG)

mesclarem os auspícios da cooperação e da competitividade, essas conexões suscitam oportunidades para que a grande corporação incremente, de modo rápido e flexível, as suas capacidades de aprendizagem e de inovação. O segundo evidencia a prática que mira valorizar capital fundiário e obter rendas diferenciadas da terra, por meio da adequação de uma gleba periurbana há tempos pertencente ao Grupo em destaque. Obtém-se, assim, a valorização do capital imobiliário, um processo cuja assertiva dos governos é assaz ativa.

Trata-se de uma dinâmica de migração de capitais que faz do solo urbano um foco de investimento não apenas para reserva de valor, mas, também, para geração de mais valor. Como diz Lefebvre (1999), nos momentos em que as incertezas envolvem o capital produtivo, os grupos econômicos direcionam montantes de capitais para o setor imobiliário, para a absorção dos (possíveis) choques. A produção do espaço urbano, nesse sentido, se torna condição para a reprodução do capital.

A despeito dos efeitos multiplicadores dessa estratégia serem, em algumas situações, elementares em comparação com o setor produtivo, o papel do mercado imobiliário se mostra estratégico tanto no sentido da absorção de crises como na construção de sinergias para o incremento e inovação, como destacado anteriormente. Do ponto de vista da renda diferenciada do solo urbano perante o arrefecimento da produção industrial e/ou da venda de ativos, projetos como o Granja Marileusa evidenciam, em síntese, a prática que mira valorizar o capital fundiário, angariado nos auspícios do mercado imobiliário. Nas palavras de Lefebvre:

\footnotetext{
O capital imobiliza-se no imobiliário. A economia geral (dita nacional) logo sofre com isso. Contudo, o papel e a função desse setor não deixam de crescer. Na medida em que o circuito principal, o da produção industrial corrente dos bens "mobiliários", arrefece seu impulso, os capitais serão investidos no segundo setor, o imobiliário (1999, p. 146-147).
}

Além do mais, convém frisar que a incorporação de antigos estoques periurbanos compôs notória estratégia de valorização fundiária no decurso da feitura de Uberlândia, algo expresso no espraiamento da cidade e nos vazios urbanos que ainda persistem. Tal como sinaliza Moura (2008), a expansão do perímetro dessa cidade ocorreu sem o devido planejamento. Antes, os aspectos pregressos de sua urbanização atenderam aos interesses de uma classe de proprietários fundiários privilegiada pelo poder público local, de modo que "o espaço urbano uberlandense já se iniciou fragmentado, estratificado, com áreas densamente 
OLIVEIRA, F. F; CASTILHO, D.

Redes organizacionais, sinergias locais e interações espaciais: O projeto Granja Marileusa e a atuação do Grupo Algar em Uberlândia (MG)

ocupadas, entremeadas a grandes vazios urbanos. Foi o início do que mais tarde seria denominado especulação imobiliária” (MOURA, 2008, p. 71). Logo, esse expediente não pode ser interpretado como um movimento novo, nem para a cidade e tampouco para a corporação.

O desígnio do Grupo Algar, para compor o Granja Marileusa, demonstra um outro patamar de competência e complexidade, se comparado com as práticas especulativas de outrora. Do ímpeto por maximizar as próprias externalidades, deriva a premissa multifacetada da concepção do bairro planejado, que se traduz nas formas, nos movimentos e nos conteúdos atinentes ao espaço ali em construção, de modo análogo aos apontamentos de Corrêa (2014). No que tange às recentes estratégias de incorporação imobiliária exercidas por grandes grupos econômicos, Rufino (2019, p. 370), ensina que a junção “do capital, da terra e dos sofisticados instrumentos financeiros mobilizados dão relevo às implicações e particularidades desses agentes hegemônicos na produção do espaço".

Portanto, o arbítrio que deu contornos ao Granja Marileusa ocorre mediante a associação com diferentes promotores imobiliários, tanto para a criação de um espaço funcionalmente distinto como da procura por induzir a concentração geográfica dos ingredientes que são indispensáveis à presente arquitetura multifuncional da corporação. $\mathrm{O}$ alinhamento do aparato institucional dos governos continua indispensável ${ }^{14}$, como sugerem os incentivos fiscais para firmas tecnológicas ou a própria a adequação infraestrutural na área do entorno do bairro planejado, assim retratada no sintomático exemplo da Figura 6.

\footnotetext{
${ }^{14}$ No dia 10/11/2019, uma reportagem veiculada pela Rede Globo de televisão, em seu semanal denominado "Fantástico", expôs um esquema de corrupção instalado na Secretaria Municipal de Planejamento Urbano de Uberlândia (SEPLAN), envolvendo agentes públicos e diversos incorporadores imobiliários atuantes na cidade. Segundo a manchete, investigações do Ministério Público de Minas Gerais indicam que o empreendimento Granja Marileusa efetuou pagamentos na forma de "mensalinho" aos servidores da Seplan, para que os projetos urbanísticos fossem aprovados mais facilmente. De acordo com a denúncia oferecida pelo Ministério Público mineiro, entre os anos de 2015 e 2017, o Granja Marileusa teria transferido R\$ 220 mil aos servidores da mencionada secretaria (FANTÁSTICO, 2019). Ademais, o periódico Diário de Uberlândia (2019) publicou uma lista das empreiteiras que uma lista contendo as empresas envolvidas no esquema. Todas as incorporadoras que atuam no Granja Marileusa foram listadas.
} 
OLIVEIRA, F. F; CASTILHO, D.

Redes organizacionais, sinergias locais e interações espaciais: O projeto Granja Marileusa e a atuação do Grupo Algar em Uberlândia (MG)

Figura 6 - Uberlândia: obras de adequação da Av. José Alves Gassani no acesso ao Granja Marileusa, 2019

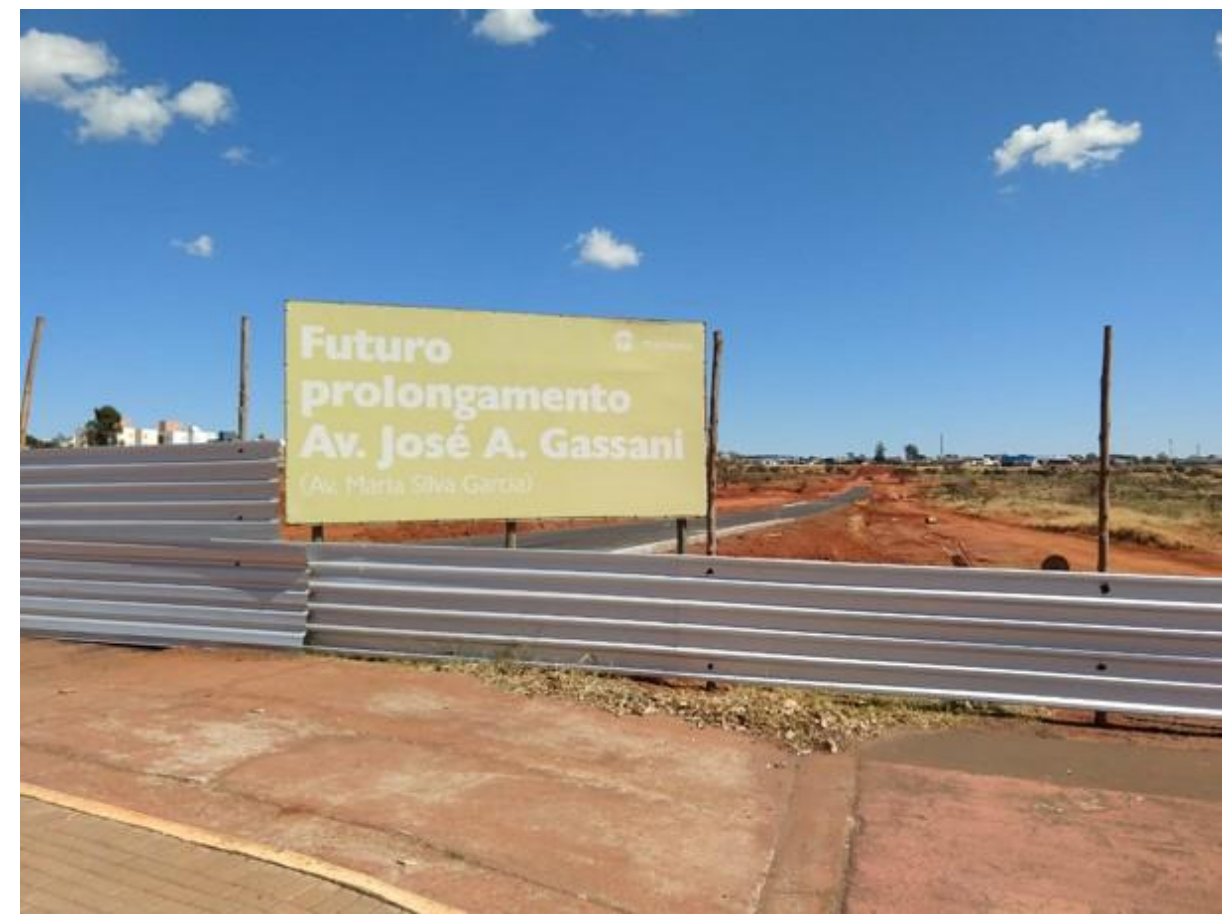

Fonte: dos autores (set. 2019).

As sinergias reticulares fomentadas pelo Grupo Algar objetivam engendrar a concentração de atividades distintas nos espaços onde a corporação mantém as suas estruturas decisórias. Tanto nas ações em corporate venture como no intento de transformar o Granja Marileusa num "distrito de inovação", a organização em rede autoriza uma série de subcontratos, de sinergias e de parcerias que conferem volume e efetividade às interações entre os diversos atores empenhados. Como bem anotou Capra, quanto mais pessoas estiverem engajadas em redes como essas, mais desenvolvidas e sofisticadas serão, "e mais bem preparada estará a organização para aprender e responder criativamente a novas circunstâncias (CAPRA, 2008, p. 25). A vivacidade das organizações, nesses termos, está nas comunidades de práticas.

\section{CONSIDERAÇÕES FINAIS}

O caráter expansivo da acumulação de capital opera em face do arbítrio que fomenta, nos pontos de comando, arranjos organizacionais menos rígidos, a exemplo das redes relacionais e do enfoque em fazer circular habilidades táticas. Como escreveu Harvey 
OLIVEIRA, F. F; CASTILHO, D.

Redes organizacionais, sinergias locais e interações espaciais: O projeto Granja Marileusa e a atuação do Grupo Algar em Uberlândia (MG)

(2005, p. 51), expansão geográfica e concentração geográfica "são ambas consideradas produtos do mesmo esforço para criar novas oportunidades para a acumulação de capital”.

A rede organizacional fomentada pelo Grupo Algar insta conectar atores em múltiplas escalas, arbítrio amparado pelo estrato técnico-reticular difuso no espaço geográfico. Em Uberlândia, o desígnio que persegue reforçar as vantagens circulares uniu-se estrategicamente à incorporação de um estoque periurbano pertencente ao próprio Grupo, dando origem ao bairro Granja Marileusa. Por efeito da indução de usos diferenciados do solo urbano, obtém-se a valorização do capital imobiliário, um processo que não prescinde das assertivas dos governos. O "retorno" do multilocalizado Grupo Algar sobre Uberlândia exemplifica o modo pelo qual os agentes hegemônicos significam o lugar conforme as suas demandas particularistas.

Diante do exposto, é possível inferir que a organização em rede do Grupo Algar é baseada no movimento sincrônico que o leva a configurar uma série de segmentações técnicas, sociais e territoriais hierarquicamente tipificadas. A lógica expansível é alinhada à indução de redes contíguas que consubstanciam uma interação localizada e auto reprodutora, um estrato horizontal pautado na cooperação informacional entre diferentes atores. Em realidade, as associações em rede ajuízam a justaposição entre horizontalidades e verticalidades, tal como explicado por Santos (2012), tornando-se a imagem espacial da acumulação multiescalar de grandes corporações.

\section{REFERÊNCIAS}

ABSTARTUP. Associação Brasileira de Startups. Disponível em: $<$ https://abstartups.com.br/>. Acesso em ago. 2019.

AGÊNCIA INTELECTO. Diretoria de Inovação e Transferência de Tecnologia da Universidade Federal de Uberlândia. Depósito de patentes. 2019. Disponível em: <http://www.propp.ufu.br/acontece/2019/06/depositos-de-pedidos-de-patente-por-unidadeacademica $>$. Acesso em ago. 2019.

ALGAR. Relatório de Sustentabilidade de 2016. Disponível em: <https://www.algar.com.br/>. Acesso em maio 2019.

Relatório de Sustentabilidade de 2018. 2019. Disponível em:

<https://www.algar.com.br/>. Acesso em maio 2019. 
OLIVEIRA, F. F; CASTILHO, D.

Redes organizacionais, sinergias locais e interações espaciais: O projeto Granja Marileusa e a atuação do Grupo Algar em Uberlândia (MG)

ALGAR TELECOM. Relatório de Sustentabilidade de 2018. Disponível em

$<$ https://algar2019.nambbu.com.br/>. Acesso em ago. 2019.

ALSOL. Disponível em <http://alsolenergia.com.br/>. Acesso em ago. 2019.

ANEEL. Agência Nacional de Energia Elétrica 2018. Banco de Informações de Geração BIG. Disponível em:

<http://www2.aneel.gov.br/aplicacoes/capacidadebrasil/GeracaoTipoFase.asp>. Acesso em ago. 2019.

APROTEC. Associação Nacional de Entidades Promotoras de Empreendimentos Inovadores. Estudo de impacto econômico: segmento de incubadoras de empresas do Brasil. Brasília: APROTEC/SEBRAE, 2016. Disponível em:

<http://www.anprotec.org.br/Relata/18072016\%20Estudo_ANPROTEC_v6.pdf>. Acesso em ago. 2019.

BANDO DE DADOS INTEGRADOS - BDI. 2018. Disponível em:

<https://www.uberlandia.mg.gov.br/prefeitura/secretarias/planejamento-urbano/banco-dedados-integrados/>. Acesso em ago. 2019.

BENKO, Georges. Economia urbana e regional na virada do século. In: RIBEIRO, M.; MILANI, C. (Orgs.). Compreendendo a complexidade socioespacial comtemporânea: o território como categoria de diálogo interdisciplinar. Salvador: EDUFBA, 2009.

BIT MAGAZINE. Tudo o que importa em TI está aqui. Disponível em: <https://www.bitmag.com.br/>. Acesso em: set. 2019.

CAPRA, Fritjof. Vivendo redes. In: DUARTE, Fábio; QUANDT, Carlos; SOUZA, Queila. (Orgs.). O tempo das redes. São Paulo: Perspectiva, 2008.

CARVALHO, Antonio G.; RIBEIRO, Leonardo L.; FURTADO, Cláudio V. A indústria de private equity e venture capital: primeiro censo brasileiro. 2005. FGV Biblioteca Digital. Disponível em: <https://bibliotecadigital.fgv.br/dspace/handle/10438/13444>. Acesso em ago. 2019.

CASTELLS, Manuel. A sociedade em rede. Tradução de Roneide Venancio Majer. $8^{\mathrm{a}}$ ed. São Paulo: Paz e Terra, 2005.

CHANDLER, Alfred D (1990). Escala, escopo e capacidade organizacional. In: McCRAW, Thomas K. (Org.). Alfred Chandler: ensaios para uma teoria histórica da grande empresa. Rio de Janeiro: Fundação Getúlio Vargas, 1998. p. 304-342.

CORRÊA, Roberto L. Trajetórias Geográficas. 7 ed. Rio de Janeiro: Bertrand Brasil, 2014.

DE FOUNIER. Disponível em <https://www.defprojetos.com/granja-marileusa > Acesso em ago. 2019. 
OLIVEIRA, F. F; CASTILHO, D.

Redes organizacionais, sinergias locais e interações espaciais: O projeto Granja Marileusa e a atuação do Grupo Algar em Uberlândia (MG)

DIÁRIO DE UBERLÂNDIA. Ação lista empresas investigadas em esquema com exservidores da Seplan. 2019. Disponível em:

<https://diariodeuberlandia.com.br/noticia/23569/acao-lista-empresas-investigadas-emesquema-com-ex-servidores-da-seplan>. Acesso em nov. 2019.

DIÁRIO DO COMÉRCIO. 2018. Algar Ventures Open Auxilia empresas a crescer em média mais de $\mathbf{1 0 0 \%}$. Disponível em: < http://diariodocomercio.com.br/sitenovo/algarventures-open-auxilia-empresas-a-crescer-em-media-mais-de-100/>. Acesso em ago. 2019.

ENERGISA. Energisa conclui compra da Alsol. 2019a. Disponível em <http://grupoenergisa.com.br/Paginas/noticia.aspx?id=185>. Acesso em ago. 2019.

Perfil corporativo. 2019b. Disponível em: <https://ri.energisa.com.br/aenergisa/perfil-corporativo>. Acesso em ago. 2019.

FANTÁSTICO. Cadê o dinheiro que estava aqui? Edição de Renato Nogueira Neto; Alexandre Rodrigues; Eric Romar. Rede Globo, 2019. Disponível em: <https://www.youtube.com/watch?v=s1pnmcPfbZ0\&t=319s>. Acesso em nov. 2019.

FISCHER, André. (1978). Transportes e localização industrial. In: FIRKOWSKI, Olga L. C. F.; SPOSITO, Eliseu S. (Org.). Indústria, ordenamento e território: a contribuição de André Fischer. São Paulo: Expressão Popular - UNESP (Programa de Pós Graduação em Geografia), 2008.

FUJITA, M.; KRUGMAN, P.; VENABLES, A. Economia espacial: urbanização, prosperidade econômica e desenvolvimento humano no mundo. Tradução de Bazán Tecnologia Linguística. São Paulo: Futura, 2002.

GOMES, Maria T. S. Espaço, inovação e novos arranjos espaciais: algumas reflexões. In: OLIVEIRA, Floriano G.; OLIVEIRA, Leandro D.; TUNES, Regina; PESSANHA, Roberto M. (Orgs.). Espaço e economia: geografia econômica e a economia política. Rio de Janeiro: Consequência, 2019. p. 163-196.

GRANJA MARILEUSA. Disponível em: <https://www.granjamarileusa.com.br/o-bairro/>. Acesso em ago. 2019.

HARVEY, David. A produção capitalista do espaço. São Paulo: Annablume, 2005. 252p.

. Os limites do capital. Tradução de Magda Lopes. 1ed. São Paulo: Bointempo, 2013. Recurso eletrônico. 697p.

ISTOÉ. Dinheiro. O salto digital da Algar Tech. Disponível em:

<https://www.istoedinheiro.com.br/o-salto-digital-da-algar-tech/>. Acesso em ago. 2019.

LEFEBVRE, Henri. A Revolução Urbana. Belo Horizonte: Editora UFMG, 1999. 
OLIVEIRA, F. F; CASTILHO, D.

Redes organizacionais, sinergias locais e interações espaciais: O projeto Granja Marileusa e a atuação do Grupo Algar em Uberlândia (MG)

MARKUSEN, Ann. Mudança econômica regional segundo o enfoque centrado no ator. In: DINIZ, Clélio C.; LEMOS, Mauro B. Economia e Território. Belo Horizonte: Editora da UFMG, 2005.

MAZZALI, Leonel. $\mathbf{O}$ processo recente de reorganização agroindustrial: do complexo à organização "em rede”. São Paulo: Editora UNESP, 2000. 175p.

MOURA, Gerusa G. Condomínios horizontais/loteamentos fechados e a vizinhança (in)desejada: um estudo em Uberlândia/MG. 270f. Tese. (Doutorado em Geografia) Instituto de Geografia da Universidade Federal de Uberlândia, Uberlândia, 2008.

MUSEU DA PESSOA. História de Eleusa Garcia Melgaço. 2004. Disponível em: <https://www.museudapessoa.net/pt/conteudo/historia/a-filha-do-visionario-46055>. Acesso em dez. 2019.

NORTH, Douglass. Instituições, mudança institucional e desempenho econômico. Tradução de Alexandre Morales. São Paulo: Três Estrelas, 2018. 255p.

PIRES DO RIO, Gisela. Organizações empresariais, trajetórias espaciais e racionalidade: espaço e tempo de uma empresa de celulose. Território. Rio de Janeiro, ano V, n. 8, p. 101119, jan./jun. 2000.

A espacialidade da economia: superfícies, fluxos e redes. In: CASTRO, Iná E. de; GOMES, Paulo Cesar da C.; CORRÊA, Roberto L. (Org.). Olhares geográficos: modos de ver e viver o espaço. Rio de Janeiro: Bertrand Brasil, 2012. p. 155-187.

RUFINO, Beatriz. Grandes grupos econômicos na produção do espaço: um olhar sobre a atuação imobiliária do Grupo Votorantin. In: OLIVEIRA, Floriano G.; OLIVEIRA, Leandro D.; TUNES, Regina; PESSANHA, Roberto M. (Orgs.). Espaço e economia: geografia econômica e a economia política. Rio de Janeiro: Consequência, 2019. p. 367-398.

SANTOS, Milton. A natureza do espaço: técnica e tempo, razão e emoção. 4 ed. São Paulo: EDUSP, 2012.

SILVA. Antônio P. da. Com o suor do teu rosto: biografia do Comendador Alexandrino Garcia. Uberlândia: SABE, 1993. 152 p.

UBERLÂNDIA. Lei Complementar n ${ }^{\circ} 629$, de 7 de dezembro de 2017. Institui no âmbito do Município o Programa Inova Uberlândia, cria o Polo Tecnológico Sul, revoga a Lei complementar $n^{\circ} 588$ de 25 de junho de 2014 e suas alterações, e as Leis $n^{\circ} 8.874$ de 7 de dezembro de 2004, e 11.081, de 14 de março de 2012, e dá outras providências.

Dados geoeconômicos de Uberlândia. 2018. Disponível em:

<http://www.uberlandia.mg.gov.br/2014/secretariapagina/27/3086/dados_geoeconomicos.html>. Acesso em ago. 2019. 
OLIVEIRA, F. F; CASTILHO, D.

Redes organizacionais, sinergias locais e interações espaciais: O projeto Granja Marileusa e a atuação do Grupo Algar em Uberlândia (MG)

WILLIAMSON, Oliver. The modern Corporation: origins, evolution, atributes. Journal of Economic Literature, v. 19, n.4, p. 1.537-68, dez. 1981.

\section{Autores}

Fernando Fernandes de Oliveira - É Graduado e Mestre em Geografia pela Universidade Federal de Uberlândia (UFU) e Doutor em Geografia pela Universidade Federal de Goiás (UFG). Atualmente é Professor do Instituto Federal de Ciência e Tecnologia Goiano (IF/Goiano, Ipameri).

Denis Castilho - É Graduado, Mestre e Doutor em Geografia pela Universidade Federal de Goiás (UFG). Atualmente é Professor do Programa de Pós-Graduação em Geografia, Instituto de Estudos Sócio-Ambientais, Universidade Federal de Goiás (UFG).

Artigo recebido em: 13 de abril de $\mathbf{2 0 2 0 .}$

Artigo aceito em: 26 de junho de 2020.

Artigo publicado em: 01 de julho de 2020. 